\title{
3kW Power Supply Design with Easy Manufacturability for 48 V Bus Power Architecture
}

This paper was downloaded from TechRxiv (https://www.techrxiv.org).

\section{LICENSE}

CC BY 4.0

SUBMISSION DATE / POSTED DATE

$17-01-2022$ / 22-02-2022

\section{CITATION}

Nabih, Ahmed; Li, Qiang; Lee, Fred (2022): 3kW Power Supply Design with Easy Manufacturability for 48 V Bus Power Architecture. TechRxiv. Preprint. https://doi.org/10.36227/techrxiv.18551387.v2

DOI

10.36227/techrxiv.18551387.v2 


\title{
3kW Power Supply Design with Easy Manufacturability for $48 \mathrm{~V}$ Bus Power Architecture
}

\author{
Ahmed Nabih, Qiang Li, Member, IEEE, Fred C. Lee, Fellow, IEEE \\ Center for Power Electronics Systems \\ Bradley Department of Electrical and Computer Engineering \\ Virginia Tech, Blacksburg, VA 24061 USA \\ nabih@vt.edu, lqvt@vt.edu
}

\begin{abstract}
The increase of power requirements per server rack, especially in the $48 \mathrm{~V}$ bus architecture is demanding the increase of rated power and power density per power supply to fit as many power supplies in the server rack power shelf as possible. Due to the trade-off between fabrication cost and efficiency (running cost) of the power supply, the design of an efficient yet less laborintensive power supply is important. This paper discusses methods to design the DC-DC unit of the $3 \mathrm{~kW}$ power supply for the $48 \mathrm{~V}$ architecture with easier manufacturability and lower cost. Prototype for $400 \mathrm{~V} / 48 \mathrm{~V} 3 \mathrm{~kW} 1 \mathrm{MHz}$ is demonstrated.
\end{abstract}

Keywords - Resonant converter, $48 \mathrm{~V}$ architecture, planer magnetics.

\section{INTRODUCTION}

Datacenters have been switching focus from the $12 \mathrm{~V}$ to the $48 \mathrm{~V}$ power architecture, as shown in Fig. 1, for several reasons [1]:

- The $48 \mathrm{~V}$ power architecture has less dissipation loss on the bus as it uses higher voltage.

- A $48 \mathrm{~V}$ battery bank is connected directly to the $48 \mathrm{~V}$ bus to support the loads during energy shortage which saves the loss of the extra UPS in the $12 \mathrm{~V}$ architecture.

Recently, the demand for higher power per server rack is increasing [2], and a power supply unit with high power and high power density is needed. The power supply unit is required to deliver $3 \mathrm{~kW}$ or higher with high power density and high efficiency. In addition, simple manufacturability and assembly are crucial to reducing the cost of the power supply. This paper

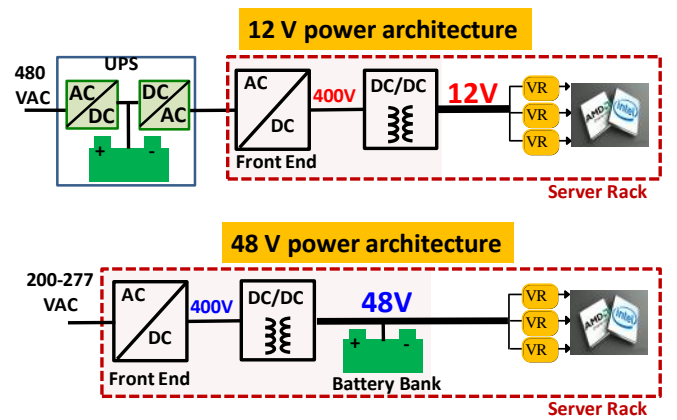

Fig.1. $12 \mathrm{~V}$ power architecture and $48 \mathrm{~V}$ architecture for datacenters focuses on the design of the DC-DC converter based on the resonant converter. Resonant converters feature soft-switching which reduces the device switching loss and allows pushing switching frequency without sacrificing device loss. The paper introduces two designs; the first one is based on a full-bridge LLC resonant circuit, and the second design is based on a fullbridge CLL converter. The converter utilizes $\mathrm{GaN}$ devices to push the switching frequency to $1 \mathrm{MHz}$, which allows to reduce the magnetic size and achieve a high power density. In addition, with the help of high frequency, the magnetic design can be switched from Litz wire magnetics [3] to planar magnetics using PCB. High power designs have significant transformer conduction loss. A matrix of transformers can help to reduce the conduction loss in the transformer winding and secondary side devices as well [4] [5]. The two introduced designs are based on a 6-layer PCB that integrates all magnetic components and active switches of the converter and introduce low profile converter design.

\section{V/48V DC-DC CONVERTER DESIGN FOR 3KW POWER SUPPLY}

Here, we introduce two design methods based on planar magnetics and easy manufacturability:

\section{A. Full-bridge LLC design with planer magnetics}

The first design is based on the well-known LLC converter. Full bridge LLC converter is used with $600 \mathrm{~V}$ GaN devices on the primary side and $150 \mathrm{~V} \mathrm{GaN}$ on the secondary side. Fig. $2 \mathrm{a}$ shows the equivalent circuit of the first design. Four elemental transformers are used to form a matrix transformer. Each elemental transformer has a 2:1 turns ratio. The secondary winding of each elemental transformer is connected to the center-tapped rectifier and the output filter capacitors of the four transformers are connected in parallel. Even though matrix transformer is beneficial from a conduction loss point of view, the concept of matrix transformer increases the size of the transformer size as it uses multiple transformers. The increase of size from matrix transformer is counteracted by the increase of switching frequency to reduce the size and magnetic integration of the four transformers [6] [7] into one double UI core as shown in Fig. 2b. The secondary and primary windings are interleaved to reduce the AC winding loss. For the LLC, a significant amount of resonant inductance value is important to achieve voltage regulation through a wide gain range. The inductance here is implemented by the means of extending the primary 


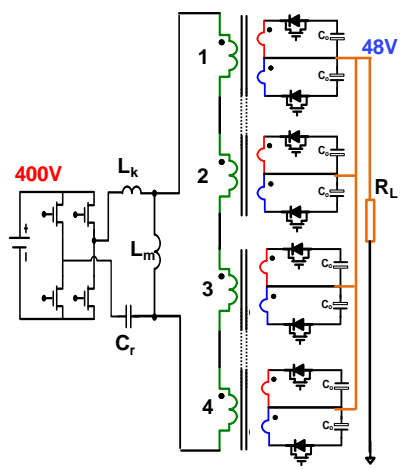

(a)

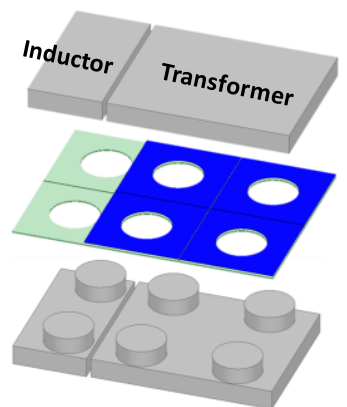

Inductor Transformer

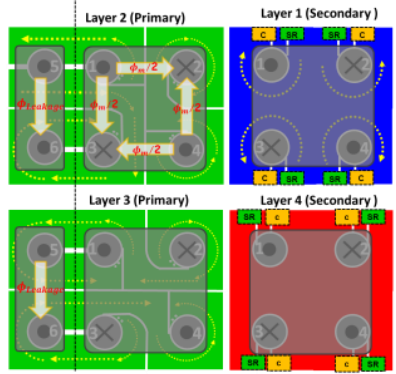

(b)

Fig.2. Fullbridge LLC converter with Matrix of four transformer. (a) circuit, (b) Implementation of transformer and inductor with 6 layer PCB (2 layers for shielding)

winding to wind an extra UI core [8] [9] [10] [11]. The matrix transformer core and inductor core can be separated or integrated into one $6 \mathrm{leg}$ core. This design integrates all magnetic and active components into one PCB. The power density of the converter is $400 \mathrm{~W} / \mathrm{in}^{3}$, and the efficiency is over 97\%. Fig. 3 shows implemented prototype of $1 \mathrm{MHz} 3 \mathrm{~kW}$ DCDC using the first design method where the whole converter including magnetic components is included in a single 6 layer PCB.

\section{B. Full-bridge CLL design with planer magnetics}

The first design with LLC implements a resonant inductor on the primary side of the transformer using UI core. The
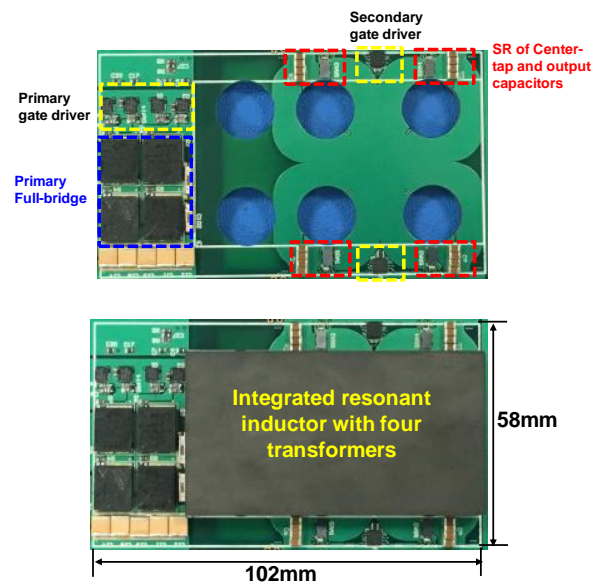

Fig.3. Generation 1: $1 \mathrm{MHz} 3 \mathrm{~kW}$ LLC converter in 6-leg core, power density $400 \mathrm{~W} / \mathrm{in} 3$ implementation of a resonant inductor comes with the expense of an extra footprint. In the second design, the resonant inductor is implemented within the matrix transformer by utilizing the transformer leakage. A fifth leg is added between the four transformer legs to confine and enhance the leakage flux of the transformer and increase the leakage inductance. However, with the original winding arrangement of the matrix transformer (fig. $2 b$ ), the winding is identical on all four legs. This symmetry in winding results in symmetry in the flux in the four legs and the resulting flux going through the $5^{\text {th }}$ center leg is zero. Therefore, the winding is rearranged as in Fig. $3 \mathrm{~b}$ to create leakage flux in the center leg by breaking the symmetry in winding between the four transformers. In the example in Fig.3, the secondary winding is relocated without making any change on the primary winding. Blue secondary is active for the first half cycle and red secondary is active for the second half cycle. This will cause leakage flux to pass through the center leg. By relocating the secondary winding, the physical leakage inductance is found on the secondary side which can be verified by using the reluctance model and finite element simulation as well. This way, this example winding structure can be used in a three-element CLL resonant circuit as shown in Fig. 3a. Different combinations of winding arrangements will result in different leakage inductance values on both primary and secondary sides.

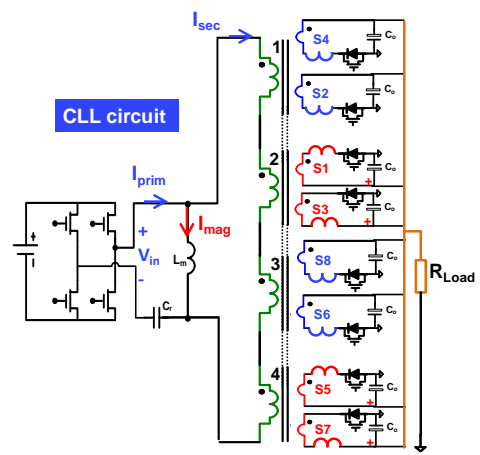

(a)

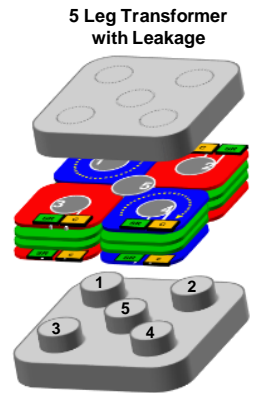

(b)
Fig.4 Fullbridge CLL converter with Matrix of four transformer. (a) circuit, (b) PCB implementation of transformer and inductor
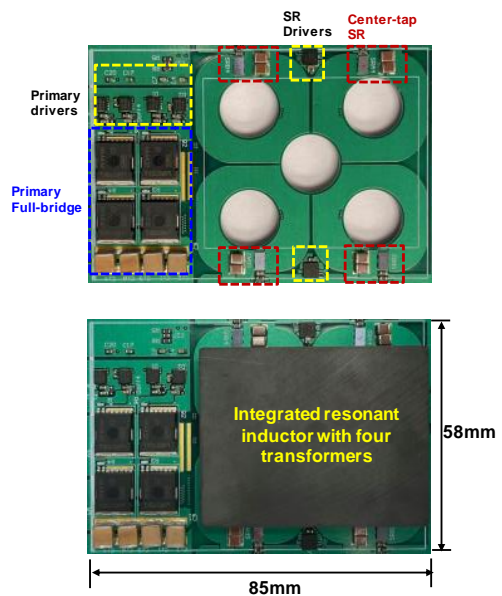

Fig.5. Generation 2: $1 \mathrm{MHz} 3 \mathrm{~kW}$ CLL converter with 5-leg core, power density $550 \mathrm{~W} / \mathrm{in}^{3}$ 


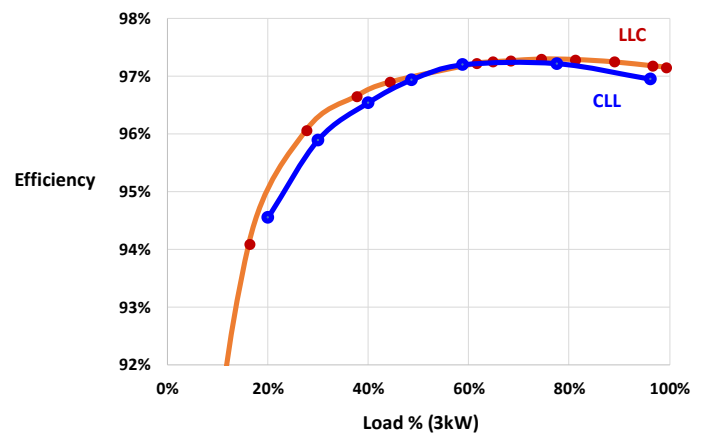

Fig.6. Tested efficiecny of LLC and CLL converters

The second design with a 5-Leg core structure provides the benefit of higher power density and smaller footprint while still using 6 layer PCB for easier manufacturability. The projected power density of this converter is $550 \mathrm{~W} / \mathrm{in}^{3}$. Further work has been done to push the efficiency of the $3 \mathrm{~kW}$ power supply design in [12] [13] [14].

As a conclusion, this paper has presented high frequency design and magnetic integration methods to provide solutions to high-efficiency high power density converters with yet easy implementation and assembly.

\section{REFERENCES}

[1] J. H. D. F. Donghwi Kim, "48V Power Delivery to Grantley Reference Board," in APEC, 2016.

[2] P. Fernandez, "Open Rack V2.1 Standard compliant 48V System Design - High Efficiency power and Lithium BBU units," in OCP summit, 2018.

[3] Delta, "DPR 3000 EnergE Single phase rectifier," Delta.

[4] E. Herbert, "High frequency matrix transformer". United States Patent US5093646A, 1989.

[5] F. C. Lee, Q. Li and A. Nabih, "High Frequency Resonant Converters: An Overview on the Magnetic Design and Control Methods," IEEE Journal of Emerging and Selected Topics in Power Electronics, vol. 9, no. 1, pp. 11-23, Feb. 2021, doi: 10.1109/JESTPE.2020.3011166..

[6] D. Huang, S. Ji, F. C. Lee, "LLC resonant converter with matrix transformer," IEEE Trans. Power Electron., vol. 29, no. 8, pp. 4339-4347, Aug. 2014.

[7] C. Fei, F. C. Lee and Q. Li, "High-Efficiency High-PowerDensity LLC Converter With an Integrated Planar Matrix Transformer for High-Output Current Applications," IEEE Transactions on Industrial Electronics, vol. 64, no. 11, pp. 9072-9082, Nov. 2017.

[8] M. H. Ahmed, A. Nabih, F. C. Lee and Q. Li, "Highefficiency, High-density Isolated/Regulated 48V Bus Converter with a Novel Planar Magnetic Structure," in IEEE Applied Power Electronics Conference and Exposition (APEC), 2019, pp. 468-475, doi: 10.1109/, 2019.

[9] M. H. Ahmed, A. Nabih, F. C. Lee and Q. Li, "Low-Loss Integrated Inductor and Transformer Structure and Application in Regulated LLC Converter for 48-V Bus Converter," IEEE Journal of Emerging and Selected Topics in Power Electronics, Vols. vol. 8, no. 1, pp, 2020.
[10] A. Nabih, M. Ahmed, Q. Li and F. C. Lee, "Simplified Optimal Trajectory Control for $1 \mathrm{MHz}$ LLC Converter with Wide Input Voltage Range," in IEEE Applied Power Electronics Conference and Exposition (APEC), 2019, pp. 212-219, doi: 10.1109/APEC.2019.8722275, 2019.

[11] Ahmed Nabih, Mohamed H Ahmed, Qiang Li, Fred C Lee, "Transient Control and Soft Start-Up for 1-MHz LLC Converter With Wide Input Voltage Range Using Simplified Optimal Trajectory Control," IEEE Journal of Emerging and Selected Topics in Power Electronics, vol. 9, no. 1, pp. 24-37, 2020.

[12] Ahmed Nabih, Rimon Gadelrab, Pranav Raj Prakash, Qiang Li, Fred C. Lee, "High Power Density $1 \mathrm{MHz} 3 \mathrm{~kW} 400 \mathrm{~V}-48 \mathrm{~V}$ LLC Converter for Datacenters with Improved Core Loss and Termination Loss," in Thirty-Sixth Annual IEEE Applied Power Electronics Conference and Exposition, 2021.

[13] A. Nabih, R. Gadelrab, Q. Li and F. C. Lee, "Dimensional Effects of Core Loss and Design Considerations for High Frequency Magnetics," in IEEE Energy Conversion Congress and Exposition (ECCE), 2021, 2021.

[14] A. Nabih and Q. Li, "Low-Profile and High-Efficiency 3 kW 400 V-48 V LLC Converter with a Matrix of Four Transformers and Inductors for $48 \mathrm{~V}$ Power Architecture for Data Centers," in IEEE Energy Conversion Congress and Exposition (ECCE), 2021, pp. 1813-18, 2021.

[15] A. Nabih, Q. Li and F. C. Lee, "Magnetic integration of matrix transformer with controllable leakage inductance". Patent U.S. Patent Application 16/864,868, filed November 5, 2020. . 